Revista Brasileira de Cartografia

ISSN 1808-0936 | https://doi.org/10.14393/revbrascartogr

Sociedade Brasileira de Cartografia, Geodésia, Fotogrametria e Sensoriamento Remoto

\title{
30 anos de Medições Gravimétricas Absolutas no Brasil
}

\section{0 years of absolute gravity measurements in Brazil}

Gabriel do Nascimento Guimarães ${ }^{1}$, Denizar Blitzkow ${ }^{2}$, Ana Cristina Oliveira Cancoro de Matos ${ }^{3}$ e Carlos Alberto Corrêa e Castro Júnior ${ }^{4}$ e Mariana Eiko Borna Inoue ${ }^{5}$

1 Universidade Federal de Uberlândia, Instituto de Geografia, Monte Carmelo, Brasil. gabriel@ufu.br.

ORCID: http://orcid.org/0000-0003-4380-4650

2 Universidade de São Paulo, Escola Politécnica, São Paulo, Brasil. dblitzko@usp.br.

ORCID: https://orcid.org/0000-0003-1412-3063

3 Centro de Estudos em Geodesia, São Paulo, Brasil. acocmatos@gmail.com.

ORCID: http://orcid.org/0000-0002-0040-588X

4 Instituto Brasileiro de Geografia e Estatística, Goiânia, Brasil. correaecastrojr@gmail.com.

ORCID: https://orcid.org/0000-0003-0276-8673

5 Universidade Federal de Uberlândia, Instituto de Geografia, Monte Carmelo, Brasil. marieiko.borba24@ hotmail.com

ORCID: https://orcid.org/0000-0002-2008-3769

Resumo: O Sistema Geodésico Brasileiro é composto por estações de referência que reúnem informações acerca da componente altimétrica, planimétrica (geocêntrica em uma definição contemporânea) e gravimétrica. Essa última componente, que nesta década alcançou maior evidência em função dos acontecimentos que a envolve, exerce um precípuo papel em áreas como a Geodésia, a Geologia e a Geofísica. Destacam-se os novos valores de altitudes de referência, baseados em números geopotenciais, apresentados pelo Instituto Brasileiro de Geografia e Estatística em julho de 2018, bem como os esforços que estão sendo despendidos para a implantação de um Sistema Internacional de Referência para Altitudes. Face ao exposto, o objetivo deste trabalho é mostrar o que o país possui em termos de medições gravimétricas absolutas, levantadas desde 1989 com a implantação da Rede Nacional de Estações Gravimétricas Absolutas. Um destaque evidenciando a remedição da referida rede, bem como os atuais esforços gravimétricos no país é apresentado. Além disso, realiza-se uma revisão sobre os métodos de medições absolutas, bem como os gravímetros empregados nesses 30 anos. Por fim, traça-se uma relação entre a distribuição de estações absolutas no país com as estações que comporão o Sistema Internacional de Referência para Altitudes.

Palavras-chave: Gravimetria. Gravímetro absoluto. RENEGA.

Abstract: The Brazilian Geodetic System is composed by reference stations that gather information about the altimetric, planimetric (geocentric in a contemporary definition) and gravimetric components. The last one plays a major role in areas such as Geodesy, Geology and Geophysics, and in this decade has achieved greater evidence of the events surrounding it. Highlights the new values of the reference heights, based on the geopotential number, presented by the Brazilian Institute of Geography and Statistics in July 2018, as well as the efforts that are being expended for the implementation of the International Height Reference System. The aim of the paper is to present the absolute gravity measurements carried out since 1989 with the National Absolute Gravimetric Network. A highlight emphasizing the reobservation in that network, as well as the current gravimetric efforts in the country is presented. Besides that, a review is provided about absolute measures methods and gravimeters employed in the last 30 years. Lastly, a relationship in drawn between absolute stations distribution in the country and the International Height Reference Frame stations.

Keywords: Gravimetry. Absolute Gravimeter. RENEGA.

\section{INTRODUÇÃO}

Diversas são as instituições que contribuíram e contribuem para o desenvolvimento gravimétrico no país. Uma breve cronologia, envolvendo os acontecimentos precípuos e as principais produtoras de 
informações gravimétricas, será apresentado a seguir. Detalhes acerca de cada uma das instituições são encontrados em (CASTRO JÚNIOR; GUIMARÃES; FERREIRA, 2018).

O início remete ao ano de 1698, quando o geógrafo francês Pierre Couplet realizou a primeira determinação gravimétrica na Paraíba utilizando um dispositivo pendular. As medições foram mencionadas por Newton, defensor da premissa do achatamento polar, no volume III dos seus Philosophiae Naturalis Principia Mathematica, na edição de 1713 (MOREIRA, 1991).

A instituição brasileira pioneira nas atividades gravimétricas é o Observatório Nacional (ON). Em outubro de 1851, foram empreendidas medições com o pêndulo de Foucault. Já nos primeiros anos do século XX, novas medições foram realizadas, utilizando-se um dispositivo tetrapendular de Sterneck. Em 1948, foram efetuadas determinações com um pêndulo Brown (ON, 1986). Em 1955, com a aquisição de um gravímetro Worden, houve o início de uma nova etapa de atividades gravimétricas sistemáticas. Um ano mais tarde, o Instituto Brasileiro de Geografia e Estatística (IBGE), outra instituição relevante no que tange à produção de informações gravimétricas, inicia suas atividades com a medição de circuitos voltados à calibração de gravímetros (IBGE, 2019).

Em 1960, a Universidade Federal do Paraná (UFPR), iniciou suas atividades gravimétricas sob a liderança de um ícone da Geodésia no Brasil, o professor Camil Gemael (VEIGA et al., 2018). Os levantamentos em campo começaram com um gravímetro Worden e contaram com o apoio da Petrobrás. O Estado do Paraná foi o primeiro palco de operações, priorizando-se a capital e municípios vizinhos (GEMAEL et al., 2002). Em 1967, um primeiro gravímetro LaCoste \& Romberg (L\&R), modelo G, foi cedido pelo Inter American Geodetic Survey (IAGS) para o ON e passou a operar em substituição ao antigo Worden.

A década de 70 presenciou vários acontecimentos na gravimetria. No decorrer do ano de 1971, houve a efetiva participação da UFPR na implantação da primeira grande rede gravimétrica mundial, a IGSN71, com a medição de duas estações principais e uma auxiliar em Curitiba. Nos anos seguintes outro trabalho de porte ocorreu na ilha de Santa Catarina, ainda contando com o gravímetro Worden. Em 1976, o L\&R número 372 foi incorporado à UFPR, reforçando quantitativa e qualitativamente os levantamentos subsequentes (DE FREITAS, 2015). Em 1977, foi a vez da Universidade de São Paulo (USP), a partir da aquisição de um gravímetro L\&R, realizar as primeiras medições nos marcos da Rede Altimétrica de Alta Precisão (RAAP). Em 1978, o ON passou a ser responsável pela implantação e manutenção da Rede Gravimétrica Fundamental Brasileira (RGFB), que possui cerca de 620 estações materializadas em vários recantos do território nacional (ON, 2019). Foi no final dos anos 1970, inserido no Projeto Levantamento Gravimétrico do Estado da Bahia, que os primeiros levantamentos terrestres foram executados pela Companhia de Pesquisa de Recursos Minerais (CPRM), utilizando um gravímetro Worden (GOMES; MOTA, 1980). Uma segunda investida só veio a ocorrer em meados dos anos 1980, no contexto do Programa Levantamentos Geológicos Básicos do Brasil (PLGB), tendo como objetivo distinguir estruturas e corpos geológicos no auxílio ao mapeamento geológico.

Em 1981, a USP e a antiga Diretoria de Geodésia e Cartografia do IBGE (DGC), iniciaram uma parceria para aprimorar as atividades de gravimetria direcionadas às necessidades geodésicas do Brasil. Em 1982, o ON estabeleceu uma linha de calibração gravimétrica na região de Itatiaia, estado do Rio de Janeiro. Este circuito é composto por cinco pontos criteriosamente materializados a fim de possibilitar a calibração de gravímetros relativos através da variação altimétrica das estações. Também merece destaque a estação gravimétrica para o acompanhamento dos efeitos de marés terrestres, implantada em 1985 pela UFPR, dedicada ao monitoramento das diferenças de atração lunissolar no centro de massa terrestre e na superfície; esta estação já recebeu mais de quinze gravímetros de diferentes institutos espalhados pelo planeta (DE FREITAS, 2015). Em 1989, outro marco pioneiro foi protagonizado pela UFPR, ao trazer para o Brasil o gravímetro absoluto JILAG-3, com o intuito de dar início à Rede Nacional de Estações Gravimétricas Absolutas (RENEGA). Contando com o apoio operacional do IBGE, foram medidas naquele ano as sete primeiras estações da RENEGA nas cidades de Brasília, Curitiba, Santa Maria, Teresina, Vassouras, Viçosa e Valinhos (GEMAEL, 1999). Detalhes sobre a RENEGA serão retomados na seção 4.

No ano de 1991, novos acontecimentos envolvendo Escola Politécnica da USP (EPUSP) motivaram uma segunda parceria ao IBGE. Foi o advento do projeto Anglo-Brazilian Gravity Project (ABGP) que pretendia ampliar a cobertura gravimétrica dos vazios existentes em terras brasileiras (GREEN; FAIRHEAD, 
1993).

No início dos anos 2000, USP e IBGE trabalharam novamente juntos, desta vez fora das fronteiras nacionais. Tratava-se do South American Gravity Studies (SAGS), nova modalidade do ABGP, que estendia o palco de operações aos países vizinhos. Ambos os projetos contavam com a parceria da Universidade de Leeds (Inglaterra) e com apoio de equipamentos e financeiro do então Defense Mapping Agency (DMA) dos Estados Unidos, hoje denominado National Geospatial-Intelligence Agency (NGA) (CASTRO JÚNIOR, 2005). Em 2004, o ON trouxe para o Brasil seu primeiro gravímetro absoluto, um FG-5. Dois anos depois chegou o segundo absoluto, um A-10. No ano de 2009 a Agência Nacional do Petróleo, Gás Natural e Biocombustíveis (ANP), com o apoio da comunidade científica, tomou a iniciativa de criar o BNDG (Banco Nacional de Dados Gravimétricos), contemplando um antigo anseio, com o objetivo maior de consolidar a base gravimétrica nacional, deixando-a prontamente acessível para cumprir as metas geocientíficas que a nação requer (ANP, 2019). Entre 2010 e 2011 a RGFB foi aquinhoada com novas estações insulares, mais precisamente em Fernando de Noronha e no Arquipélago de São Pedro e São Paulo. Em 2015 foi a vez da Ilha de Trindade. Essas operações contaram com o apoio da Marinha Brasileira (ON, 2019). Recentemente, em 2013, a EPUSP intermediou a aquisição de um gravímetro absoluto A-10 pelo Governo do Estado de São Paulo, por meio do Instituto Geográfico e Cartográfico (IGC).

Atualmente, o IBGE é a instituição que mais produz medidas gravimétricas com objetivos geodésicos no Brasil e possivelmente no continente. Além disso, exerce papel de liderança junto a diversos países da América do Sul, capacitando profissionais e auxiliando no desenvolvimento das respectivas redes nacionais de gravidade. Destarte, o presente trabalho apresenta uma revisão conceitual sobre a gravimetria absoluta, bem como os tipos de gravímetros. Destaca os esforços empreendidos para a implantação da RENEGA, bem como outras estações implantadas nos últimos 30 anos, além da remedição de algumas estações RENEGA nessa década.

\section{DETERMINAÇÃO DA ACELERAÇÃO DE GRAVIDADE: MEDIÇÕES ABSOLUTAS}

A determinação do valor da aceleração da gravidade (módulo $g$ do vetor gravidade) pode ser conduzida a partir de medições absolutas e relativas. As primeiras fornecem diretamente o valor de $g$ no local desejado; já as segundas, são decorrentes da ocupação de dois locais, sendo que, em um deles, o valor da aceleração de gravidade deve ser conhecido. Outra distinção é que nas determinações absolutas duas grandezas são medidas (no caso do pêndulo, período e comprimento), enquanto nas relativas apenas uma (comprimento).

Neste trabalho foram considerados apenas os conceitos envolvidos nas medições absolutas. Para informações sobre medições relativas consultar (GEMAEL, 1999; CASTRO JÚNIOR, 2005; CASTRO JÚNIOR; GUIMARÃES; FERREIRA, 2018).

\subsection{Método pendular}

O matemático, físico e astrônomo Christiaan Huygens, em seu livro Horologium Oscillatorium (1673), desenvolveu a formulação para o uso de pêndulos para medições gravimétricas. Classifica-se o método mais clássico, porém em desuso em três tipos de pêndulos: matemático, físico e reversível. O primeiro, tratase de um pêndulo fictício, puramente teórico. É descrito por uma massa pontual $(P)$, suspensa por um fio sem massa e inextensível de comprimento $(l)$ e que pode balançar sem fricção em torno de seu ponto de suspensão. O movimento da massa é limitado para um arco circular em torno do ponto de equilíbrio. O período $(t)$ de um pêndulo matemático pode se expresso em função do comprimento da corda $(l)$ e do valor local de $g$, por meio da expressão (1) (GEMAEL, 1999):

$$
t=2 \pi \sqrt{\frac{1}{g}}\left[1+\frac{1}{2} \operatorname{sen}^{2} \frac{\alpha}{2}+\left(\frac{1 * 3}{2 * 4}\right)^{2} \operatorname{sen}^{4} \frac{\alpha}{2}+\cdots+\left(\frac{1 * 3}{2 * 4} \ldots \frac{2 n-1}{2}\right)^{n} \operatorname{sen}^{2 n} \frac{\alpha}{2}+\cdots\right]
$$

onde $\alpha$ é a elongação máxima. 
Como dito anteriormente, o pêndulo matemático é somente um pêndulo fictício. Na realidade, o fio não será sem massa e a massa não será um ponto. O pêndulo físico é apresentado na Figura 1.

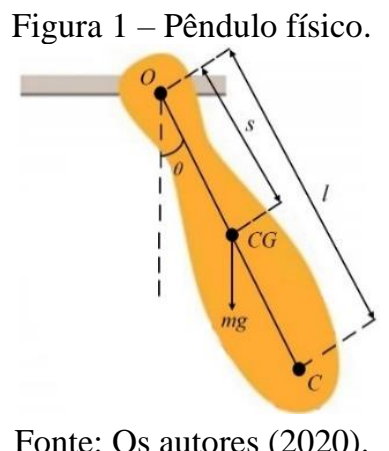

Na Figura 1, o ponto CG está localizado abaixo de O, ao longo da vertical, quando o pêndulo estiver na vertical, na posição de equilíbrio. Quando o corpo oscila, seu deslocamento em relação à vertical é descrito pelo ângulo $\theta$. Quando o corpo está na posição indicada pela Figura 1, há um torque em relação à $\mathrm{O}$, provocado pelo seu peso, cuja expressão é:

$$
\tau=-s(m g \operatorname{sen} \theta)
$$

o sinal negativo decorre do fato de que a direção positiva é a que se afasta da vertical.

O pêndulo físico também pode ser considerado um oscilador harmônico. Dessa forma, a partir da frequência angular $(\omega)$ ou do período $(T)$ é possível obter o valor de $g$ em relação à frequência, a partir da expressão (3)

$$
g=\omega^{2} \frac{\mathrm{I}}{\mathrm{ms}}
$$

para o período:

$$
T=\frac{2 \pi}{\omega} \Rightarrow T=2 \pi \sqrt{\frac{I}{m g s}} .
$$

Portanto,

$$
g=\left(\frac{2 \pi}{T}\right)^{2} \frac{I}{m s}
$$

A dificuldade do pêndulo físico consiste na determinação do momento de inércia de I, além do centro de massa do sistema e, consequentemente de s de forma acurada. Uma possibilidade de contornar tal dificuldade está no chamado pêndulo reversível. Idealizado por Henry Kater (1818), esse pêndulo possui duas extremidades (O1 e O2) alinhado com o centro de massa (CM). A distância entre os pontos extremos e CM são $l_{l}$ e $l_{2}$ (Figura 2). Uma massa móvel permite igualar os períodos em ambas as posições. 
Figura 2 - Pêndulo reversível.

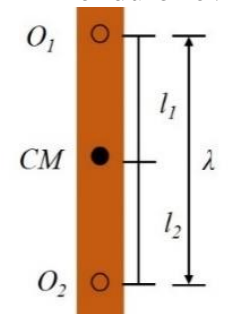

Fonte: Os autores (2020).

O momento de inércia (desconhecido) pode ser eliminado e o instrumento torna-se um gravímetro absoluto, resultando na equação (6). Detalhes do desenvolvimento podem ser encontrados em (SNEEUW, 2006).

$$
g=\left(l_{1}+l_{2}\right)\left(\frac{2 \pi}{T}\right)^{2}
$$

Portanto, se a distância entre os pontos é definida e medida de forma acurada, tem-se na expressão um gravímetro absoluto. Reescrevendo a (4) de forma simplificada:

$$
T=2 \pi \sqrt{l / g}
$$

O método pendular foi bastante utilizado até meados do século passado. Entretanto, devido a suas limitações, foi substituído pelo método de queda livre.

\subsection{Método de queda livre (free-fall)}

Quando se trata de experimentos sobre a aceleração de gravidade a partir do método de queda livre, remete-se ao século XVI quando Galileo Galilei subiu até o alto da Torre de Pisa, na Itália, para realizá-lo. A partir de então, medir a aceleração de gravidade tornou-se um objetivo científico. $O$ batizado da unidade de aceleração de gravidade como "Gal" $\left(\mathrm{cms}^{-2}\right)$, em homenagem a Galilei, é comemorado como uma etapa considerável para o desenvolvimento moderno da Geodésia e da Geofísica. Embora a recomendação seja para utilizar o Sistema Internacional de unidade (SI) $\left(\mathrm{ms}^{-2}\right)$, a comunidade tem adotado o uso das unidades miligals (mGal) ou microgals $(\mu \mathrm{Gal})$.

As primeiras medições após o feito de Galilei ocorreram somente na segunda metade do século XVII. Desde então, diversos pesquisadores conduziram medidas utilizando-se de pêndulos em diversas localidades do globo. Destaca-se Picard, em 1668 na cidade de Paris, seguido de Richer, em 1672, em Caiena. No século seguinte, expedições foram conduzidas por Maupertuis e Clairaut, na Lapônia e por Bouguer, no Equador, além de medições realizadas por Borda e Casini, em 1792 e por Laplace, em 1799 (para maiores detalhes veja ALDER, 2003; MELCHIOR, 2008). Devido à dificuldade de se medir o tempo com precisão suficiente, a partir do método de queda livre, as primeiras medições somente foram possíveis nos anos de 1960, quando o cristal e o relógio atômico se tornaram disponíveis (MELCHIOR, 2008).

O princípio do referido método (Figura 3a) é baseado na equação de movimento de um corpo em queda livre (8):

$$
m \ddot{z}=m g(z)
$$

onde $m$ é a massa, $z$ é distância ao longo do eixo vertical e $\ddot{z}=d^{2} z / d t^{2}$, isto é, a derivada da distância em relação ao tempo.

Assumindo um campo de gravidade homogêneo ao longo da distância de queda, uma dupla integração de (8) conduz a equação (9) de queda livre (TORGE, 1991; SNEEUW, 2006; TORGE; MÜLLER, 2012): 


$$
\mathrm{z}(t)=\frac{1}{2} g t^{2}+z_{0}+\dot{z}_{0} t
$$

As constantes de integração $z_{0}$ e $\dot{z}_{0}$ representam a posição e velocidade do corpo em $t=0$. Na prática não é possível iniciar a medição exatamente quando $z_{0}=\dot{z}_{0}=0$. O que ocorre é iniciar a medida em um determinado ponto da trajetória de queda. Dessa forma, $z_{0}$ e $\dot{z}_{0}$ são desconhecidos. Em consequência três pares de medidas $\left(t_{i}, z_{i}\right)$ devem ser conhecidos. No caso de se ter exatamente três medidas (Figura 3a), os parâmetros iniciais são eliminados resultando em:

$$
g=2 \frac{\left(z_{3}-z_{1}\right)\left(t_{2}-t_{1}\right)-\left(z_{2}-z_{1}\right)\left(t_{3}-t_{1}\right)}{\left(t_{3}-t_{1}\right)\left(t_{2}-t_{1}\right)\left(t_{3}-t_{2}\right)}
$$

Para uma subida e descida simétrica, a massa de teste é lançada para cima e retorna de volta depois de atingir o ápice (Figura 3b). Logo, é possível medir o tempo na mesma posição durante a subida e descida da massa.

Figura 3 - Diagrama distância-tempo. Figura 3a) representa o método queda livre. A Figura 3b) o método de subida (rise) e descida (fall) simétrico.

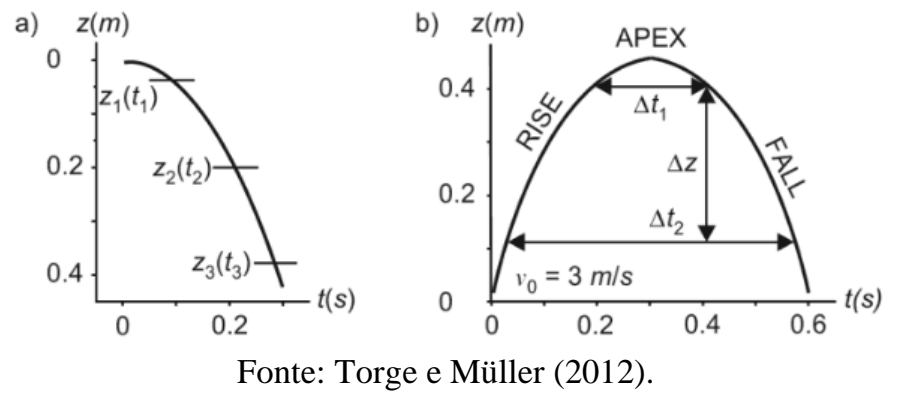

Na prática, mais medidas são realizadas durante o experimento de queda para fornecer um problema sobre determinado, isto é, mais equações do que incógnitas. Ao invés de somente considerar a queda da massa é possível lançá-la verticalmente e medir o tempo que ela leva para cair novamente. Com o avanço tecnológico dos aparelhos resultando em medições cada vez mais precisas, a mudança na aceleração de gravidade ao longo do eixo vertical deve ser levada em conta (campo de gravidade não homogêneo). Para tanto, introduzindo $\partial g / \partial z=g_{z}$, a expressão (8) se torna:

$$
m \ddot{z}=m\left(g_{0}+g_{z} z\right)
$$

$\operatorname{com} g_{0}=g$ na posição de descanso $z=0$. Uma integração dupla de (11) leva à seguinte expressão:

$$
z=\frac{g_{0}}{g_{z}}\left(\cosh \sqrt{g_{z}} t-1\right)
$$

para $z_{0}=\dot{z}_{0}=0$. Um desenvolvimento em série de $z$ (até ordem $t^{4}$ ) incluindo $z_{0}$, resulta na equação de observação (13) (COOK, 1965):

$$
z=z_{0}\left(1+\frac{1}{2} g_{z} t^{2}\right)+\dot{z}_{0}\left(1+\frac{1}{6} g_{z} t^{3}\right)+\frac{1}{2} g_{0}\left(t^{2}+\frac{1}{12} g_{z} t^{4}\right)+\cdots
$$

onde o gradiente vertical é geralmente determinado por meio de medição com gravímetro relativo.

Atualmente, a precisão nas observações gravimétricas absolutas é da ordem de $10^{-9} \mathrm{Gal}$ ou $10^{-8} \mathrm{~ms}^{-2}$. Logo, de acordo com a expressão (9) para uma distância de queda de 0,2 m (tempo de queda de 0,2 s), uma precisão de $0,2 \mathrm{~nm}$ e $0,1 \mathrm{~ns}$ é requerida para posição e tempo, respectivamente. Isso é alcançado por meio de medidas de distância interferométrica e cronometragem eletrônica. Para os gravímetros absolutos, um laser 
polarizado é utilizado como padrão de comprimento, enquanto um relógio de rubídio como padrão de tempo. A Figura 4 ilustra o princípio de funcionamento de um gravímetro de queda livre que utiliza a interferometria a laser.

Figura 4 - Princípio de funcionamento de um gravímetro que utiliza a interferometria a laser.

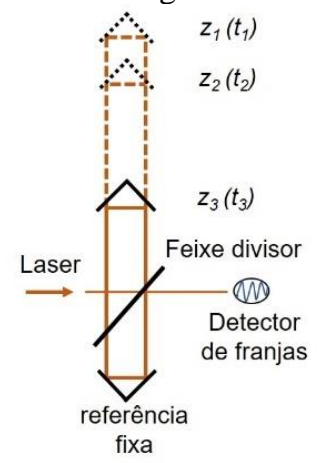

Fonte: Os autores (2020).

\section{GRAVÍMERTOS ABSOLUTOS}

Os gravímetros absolutos comumente utilizam o princípio de queda livre. Estes aparelhos são sensíveis e volumosos, o que dificulta seu transporte. O FG-5, por exemplo, opera de maneira fixa em laboratório, enquanto o A-10 foi desenvolvido para operar também em campo. Nos laboratórios, as medidas são conduzidas em locais muito estáveis, sob condições especiais de temperatura e umidade e, de preferência, em pilares de concreto ou bases incrustadas na rocha. No campo, são escolhidos locais com alguma estabilidade, de fácil acesso ao veículo, ao abrigo do sol, chuvas e ventos. Em geral, centenas de medições são realizadas para se obter o valor absoluto da aceleração de gravidade final, depois de um tratamento estatístico.

Conforme mencionado anteriormente, somente a partir dos anos 60 medições gravimétricas utilizando o princípio de queda livre foram conduzidas. O Bureau International de Poids et Mésures (BIPM), criado em 1875 na França, teve notória contribuição para o desenvolvimento de equipamentos que utilizassem o princípio de queda livre. Nomes como Amédée Guillet, Charles Volet e Åke Thulin, contribuíram para os avanços científicos dessa temática. Entretanto, deve-se ao japonês Akihiko Sakuma (que ingressou no BIPM em 1960) com colaboração de outros membros do BIPM o desenvolvimento do primeiro gravímetro absoluto. O equipamento estacionário possuía $2,8 \mathrm{~m}$ de altura e pesava $850 \mathrm{~kg}$. Em 1962, Sakuma obteve a precisão de $\frac{\Delta g}{g}=7,3 \times 10^{-8}$ (AMALVICT, 2010). Consciente da necessidade de um equipamento transportável para estabelecer a Rede Internacional de Padronização de Gravidade de 1971 (International Gravity Standardization Net 1971 - IGSN71), ele juntamente com outras instituições iniciou a tarefa. Em colaboração com o Istituto di Metrologia "G. Colonnetti” (IMGC), na Itália, entre os anos de 1968 a 1974 construíram o primeiro protótipo (Figura 5a). O princípio era muito similar ao equipamento estacionário do BIPM (subida e descida simétrica), porém com dimensão $(1,4 \mathrm{~m})$ e peso menores $(100 \mathrm{~kg})$ (AMALVICT, 2010). 
Figura 5 - a) Primeiro protótipo transportável IMGC-BIPM e b) Sakuma operando o equipamento GA-60 em 10 de maio de 1985.

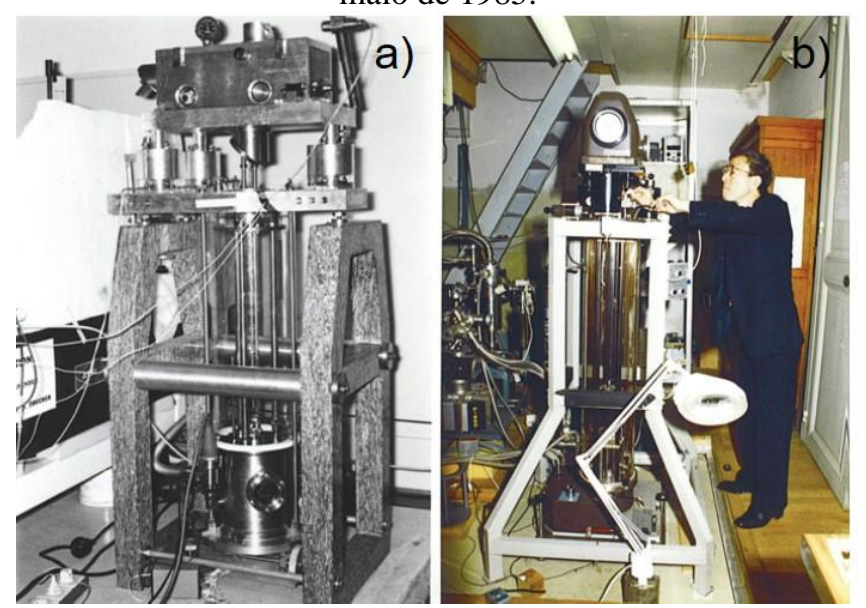

Fonte: Amalvict (2010).

\subsection{JILAG}

Desenvolvido pelo Joint Institute for Laboratory Astrophysics (JILA), em Boulder, nos Estados Unidos, o JILAG foi apresentado à comunidade no início da década de 80 (FALLER et al., 1983). Ao todo 6 equipamentos foram fabricados, sendo que o JILAG-3 foi empregado no Programa de Gravidade Absoluta na América do Sul (IFE Absolute Gravity Program "South America”) que contemplou o estabelecimento da RENEGA (TORGE et al., 1994). O aparelho foi baseado no princípio de queda livre, além de utilizar da interferometria laser, a partir do interferômetro Michelson. Portátil e transportável em um furgão, o equipamento possuía capacidade de medida a cada $2 \mathrm{~s}$ e uma distância de queda de $20 \mathrm{~cm}$, além de uma acurácia de 3-5 $\mu$ gal (FALLER et al., 1983; TORGE, 1991; NIEBAUER et al., 1995). A Figura 6a ilustra o equipamento empregado de 1986 a 2000 pela Universidade de Hannover, enquanto a Figura 6b elucida o princípio de funcionamento.

Figura 6 - a) Gravímetro JILAG e b) princípio de funcionamento.

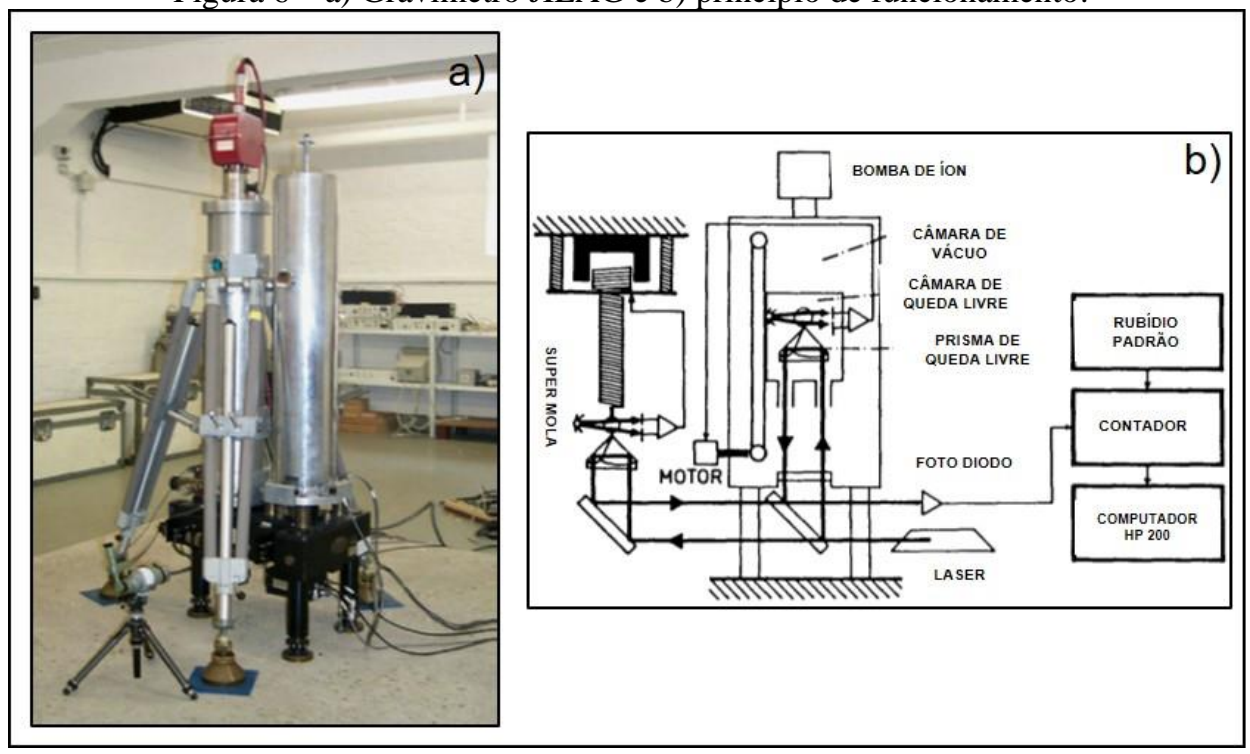

Fonte: 6a) Timmen et al. (2008) e 6b) Adaptada de Torge et al. (1987).

Nesse tipo de equipamento (Figura 6), o feixe de laser produzido pelo interferômetro é dividido em duas partes. Uma parte incide sobre um prisma fixo engastado em uma mola. A segunda parte é incidida em um segundo prisma, em queda livre, e situado no interior da câmara de vácuo. Conforme a posição do prisma em queda livre, o retorno das duas partes do feixe pode estar em fase ou fora de fase. A análise do padrão do feixe e das franjas produzidas pelo prisma durante a queda livre, recebido pelo fotodiodo, permite determinar 
o tempo e a posição do prisma em queda livre, uma vez conhecidas a velocidade da luz e o comprimento de onda do laser incidente (TORGE et al., 1987).

\subsection{FG-5}

Em 1990, o Instituto Nacional de Padrões e Tecnologia (National Institute of Standards and Technology - NIST) e a Administração Nacional Oceânica e Atmosférica (National Oceanic and Atmospheric Administration - NOAA), ambas agências pertencentes ao Departamento de Comércio dos Estados Unidos, juntamente com o Instituto de Geodésia Aplicada (Institut Fuer Angewandte Geodaesie - IFAG), da Alemanha, uniram esforços para o desenvolvimento de uma nova geração de gravímetros absolutos (CARTER et al., 1994; NIEBAUER et al., 1995). Batizado de FG-5 (Figura 7a), este equipamento era significativamente menor que o JILAG, mais fácil de implantar, mais robusto, e requeria muito menos atenção durante as operações do que os instrumentos JILAG.

O princípio de medida deste aparelho é similar ao seu antecedente. As diferenças se concentraram na distância da queda na câmara a vácuo $(33 \mathrm{~cm})$ e no tipo de interferômetro utilizado; enquanto o JILAG utilizou o Michelson, os desenvolvedores do FG-5 preferiram o Mach-Zender (Figura 7b). Trata-se de um interferômetro "in-line", o qual é insensível a inclinações e outros movimentos oriundos da base do interferômetro durante a queda da massa. Detalhes acerca do princípio de funcionamento deste interferômetro podem ser encontrados em Niebauer et al. (1995).

Figura 7 - a) Gravímetro FG-5 e b) princípio de funcionamento dos interferômetros Michelson e in-line.

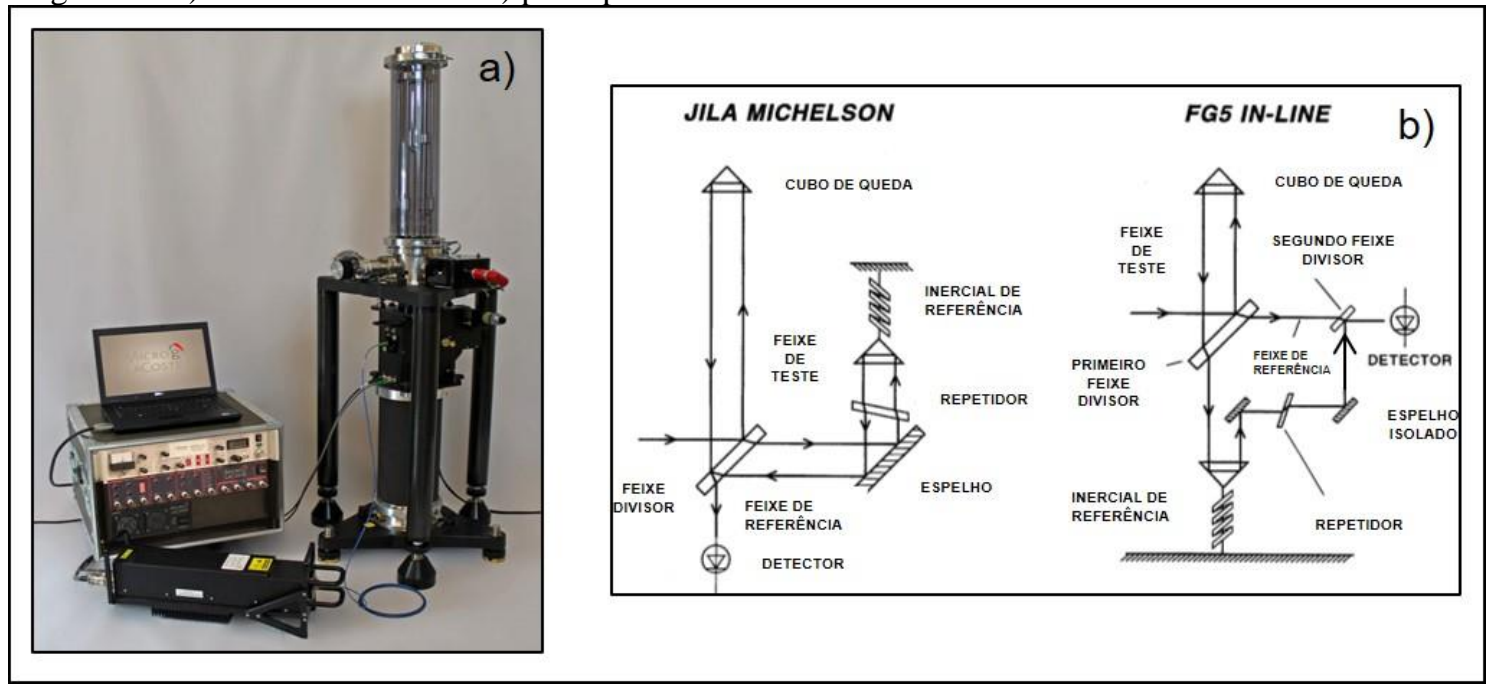

Fonte: 7a) Microg Lacoste (2008) e 7b) Adaptada de Niebauer et al. (2005).

Com acurácia absoluta de $\pm 2 \mu$ gal e precisão na medida de $\pm 1 \mu$ gal, o FG-5 passou a ser comercializado a partir de 1995. Desde 2004, a Microg Lacoste disponibilizou no mercado o FG5-X. Trata-se de uma continuação "follow on" do antecessor, na qual houve melhorias na câmara de queda e na interface eletrônica. $3.3 \mathrm{~A}-10$

O A-10 é o primeiro gravímetro absoluto fabricado para atuar em trabalhos de campo e que permite determinar a aceleração de gravidade com alta precisão. $\mathrm{O}$ equipamento foi apresentado à comunidade em 2001, possuindo acurácia absoluta de $\pm 10 \mu$ gal e precisão na medida de $\pm 5 \mu$ gal. Opera em um alcance de temperatura que varia de $-18^{\circ} \mathrm{C}$ a $+38^{\circ} \mathrm{C}$ (MICRO-G LACOSTE, 2019). O equipamento (Figura 8) é composto de duas unidades: a unidade superior, composta pela câmara de vácuo com um sistema de queda livre de uma massa (prisma); e a unidade inferior, composta por um sistema de molas (superspring), além de um interferômetro a laser. Possui ainda uma unidade eletrônica de controle para assistência ao funcionamento do aparelho a qual é acompanhada de um computador. 
Figura 8 - a) Gravímetro A-10 sob o pilar da estação Valinhos e b) Principais componentes do equipamento.

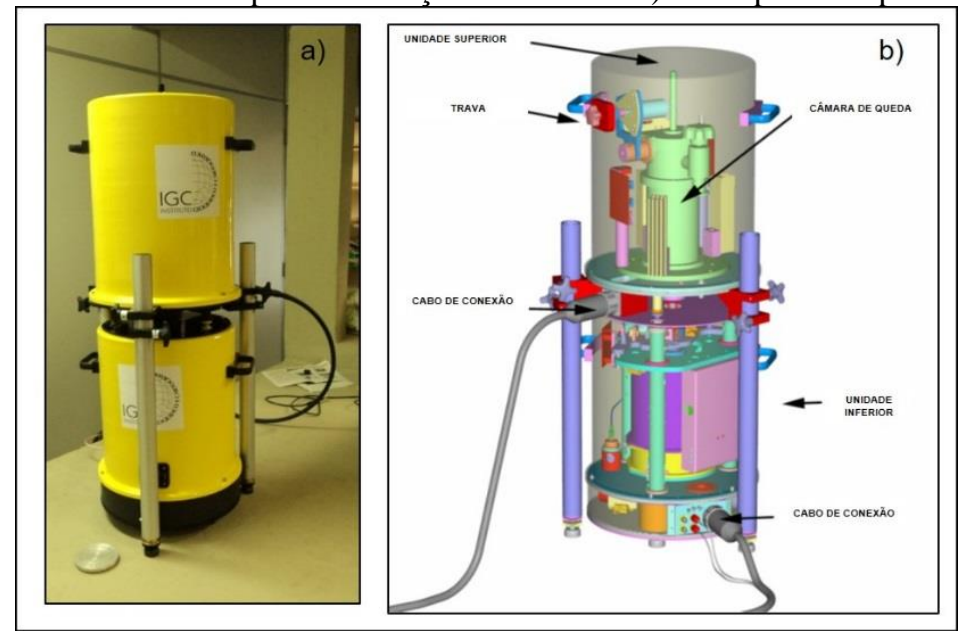

Fonte: 8a) Os autores (2020) e 8b) Adaptada de Micro-g LaCoste (2008).

\section{REDE NACIONAL DE ESTAÇÕES GRA VIMÉTRICAS ABSOLUTA - RENEGA}

Entre os anos de 1988 a 1991, um ambicioso projeto coordenado pelo Institut für Erdmessung (IFE), da Universidade de Hannover se propôs a implantar estações absolutas em quatro países no continente sulamericano. Foi intitulado de IFE Absolute Gravity Program "South America" (Programa de Gravimetria Absoluta na América do Sul). Além disso, o programa fez parte de 3 principais objetivos mais abrangentes (TORGE et al., 1994):

a) Estabelecer uma rede internacional de estações base de gravimetria absoluta (International Absolute Gravity Baseline Network - IAGBN), proposto pela Associação Internacional de Geodésia com vistas a prover um sistema de estações gravimétricas absolutas em todo o globo.

b) Apoiar e fortalecer as redes gravimétricas nacionais dos países envolvidos no programa.

c) Apoiar e fortalecer redes geodinâmicas regionais, especialmente na região da Cordilheira dos Andes.

O programa contou com a cooperação de universidades, institutos e agências dos países envolvidos. Destaca-se a participação do curso de Pós-Graduação em Ciências Geodésicas da Universidade Federal do Paraná, sob coordenação do Professor Camil Gemael (VEIGA et al., 2018).

O gravímetro JILAG-3 (seção 3.1) foi empregado nas medições que tiveram início em território brasileiro no dia 14 de fevereiro de 1989, em Teresina - Piauí (GEMAEL et al., 1990). Nas quatro semanas seguintes, as estações de Brasília (DF), Viçosa (MG), Vassouras (RJ), Valinhos (SP), Curitiba (PR) e Santa Maria (RS), foram ocupadas (Figura 9).

Em cada estação foram realizadas 5 séries de medidas de 300 ou 600 observações (quedas), totalizando 1500 ou 3000 observações, respectivamente. A correção de maré terrestre (fator de amplitude de 1,164), bem como as correções referentes ao movimento polar, correção da pressão do ar real e normal, e ainda a correção da temperatura função do comprimento de onda do laser, foram aplicadas em cada conjunto de medidas (GEMAEL et al., 1990). Os desvios-padrões de todas as medidas aceitas se concentraram entre 32 a $97 \mu \mathrm{Gal}$, sendo o primeiro valor referente à estação de Brasília (localizada cerca de $15 \mathrm{~km}$ distante da zona urbana, em uma estação sismológica da Universidade de Brasília, cuja medida foi realizada sobre um pilar de concreto com espessura de $35 \mathrm{~cm}$ ); enquanto que o segundo valor é referente à estação de Viçosa (localizada no interior de uma sala na Universidade Federal de Viçosa, sendo que a medição sofreu perturbações decorrente do tráfico de veículo nas proximidades da sala, além de um excessivo ruído no aparelho de condicionador de ar). Segundo Gemael et al. (1990), a acurácia média dos valores de aceleração de gravidade para as estações brasileiras é estimada em $\pm 10 \mu \mathrm{Gal}$. A Tabela 1 ilustra os valores obtidos para cada estação implantadas no ano de 1989. 


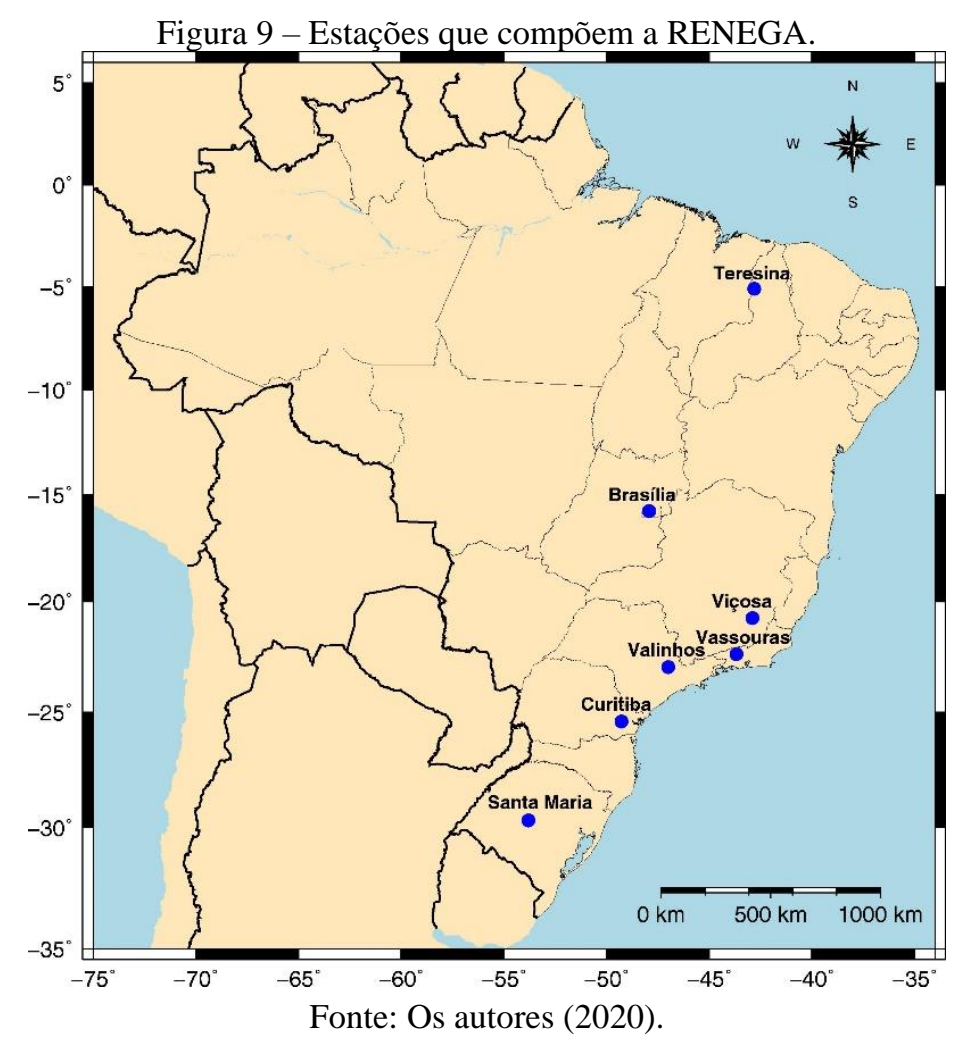

Tabela 1 - Valor de $g$ da RENEGA em 1989.

\begin{tabular}{c|c}
\hline Estações & Valor de $\boldsymbol{g}$ (mGal) \\
\hline Teresina & $978.016,343$ \\
\hline Brasília & $978.048,798$ \\
\hline Viçosa & $978.460,230$ \\
\hline Vassouras & $978.637,581$ \\
\hline Valinhos & $978.563,778$ \\
\hline Curitiba & $978.760,387$ \\
\hline Santa Maria & $979.261,636$ \\
\hline
\end{tabular}

Fonte: Adaptada de Torge et al. (1994).

Em terras brasileiras, essa primeira campanha de implantação da RENEGA terminou na fronteira entre Brasil e Uruguai, nas imediações de Santana do Livramento. Naquela ocasião os representantes do IBGE fizeram a entrega de todo o equipamento ao Serviço Geográfico Militar.

Um segundo período de remedições da RENEGA foi conduzido em 1992. Os levantamentos foram empreendidos pelo então National Geodetic Survey (NGS), atual NGA, sob a intermediação da USP. Um gravímetro absoluto JILAG-4 esteve envolvido nas medições de estações gravimétricas em Brasília, Curitiba, Fortaleza e Teresina. Nessa ocasião houve a medição de uma segunda EG absoluta em Brasília, na Reserva Ecológica do Roncador (RECOR), pertencente ao IBGE. Da mesma maneira que ocorreu na primeira etapa, coube ao IBGE apoiar operacionalmente as medições com viaturas e condutores.

Além de contribuir para o estabelecimento do IAGBN, a RENEGA possibilitou a implantação de estações de referências para a rede gravimétrica brasileira (rede fundamental ou rede de densificação), provendo o arcabouço indispensável ao posterior ajustamento da RGFB (SUBIZA PIÑA; DE SOUSA, 2001). Ademais, permitiu a determinação de uma linha norte-sul de calibração gravimétrica, com alcance de 1250 mGal, que até hoje é utilizada para a calibração e aferição de gravímetros relativos existentes no país e na América do Sul.

Desde a implantação da RENEGA, calibrações de gravímetros relativos são conduzidas periodicamente. Com o passar do tempo, os gravímetros sofrem com os desgastes e alterações do seu sistema elástico do instrumento. Assim, a calibração realizada em fábrica sofre alterações que comprometem os resultados dos levantamentos. Dessa forma, é necessário que novas calibrações sejam auferidas periodicamente. Detalhes acerca do processo de calibração podem ser encontrados em Mello (1973) e Castro 
Júnior (2005). A Figura 10 ilustra uma campanha de calibração realizada em 2013.

Figura 10 - Campanha de calibração dos gravímetros L\&R na estação Valinhos.

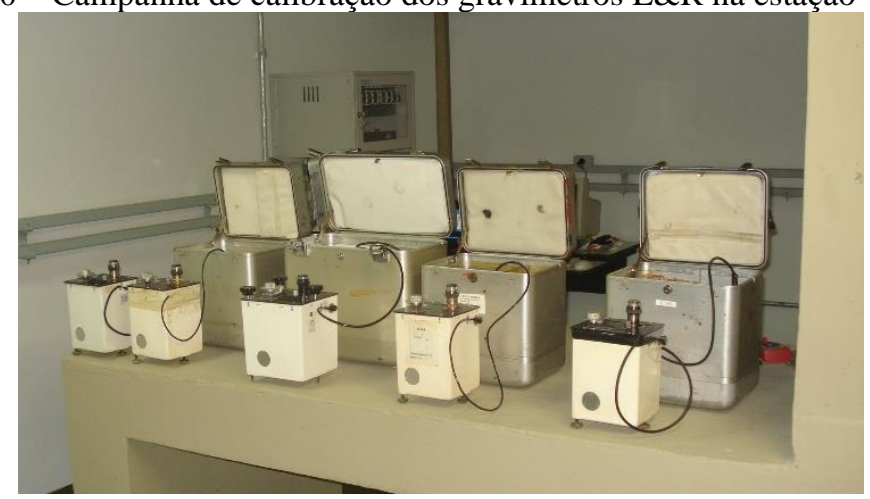

Fonte: Os autores (2020).

No Brasil, o processo de calibração mais utilizado compara as leituras instrumentais com valores acurados de $g$, derivados de duas ou mais estações gravimétricas absolutas. Nesse caso, compara-se a diferença de aceleração de gravidade obtida com o gravímetro a ser calibrado com a respectiva diferença entre as duas estações absolutas. A escolha dos pares de estações deve contemplar a mesma região de operação a ser trabalhada pelo gravímetro (INOUE et al., 2018).

\section{OUTRAS MEDIÇÕES ABSOLUTAS NO PAÍS}

Entre os anos de 2006 a 2008 o ON, responsável pela rede gravimétrica fundamental do país, utilizando um gravímetro micro-g LaCoste A-10 n 11 realizou cerca de 20 medições absolutas no país (Figura 11).

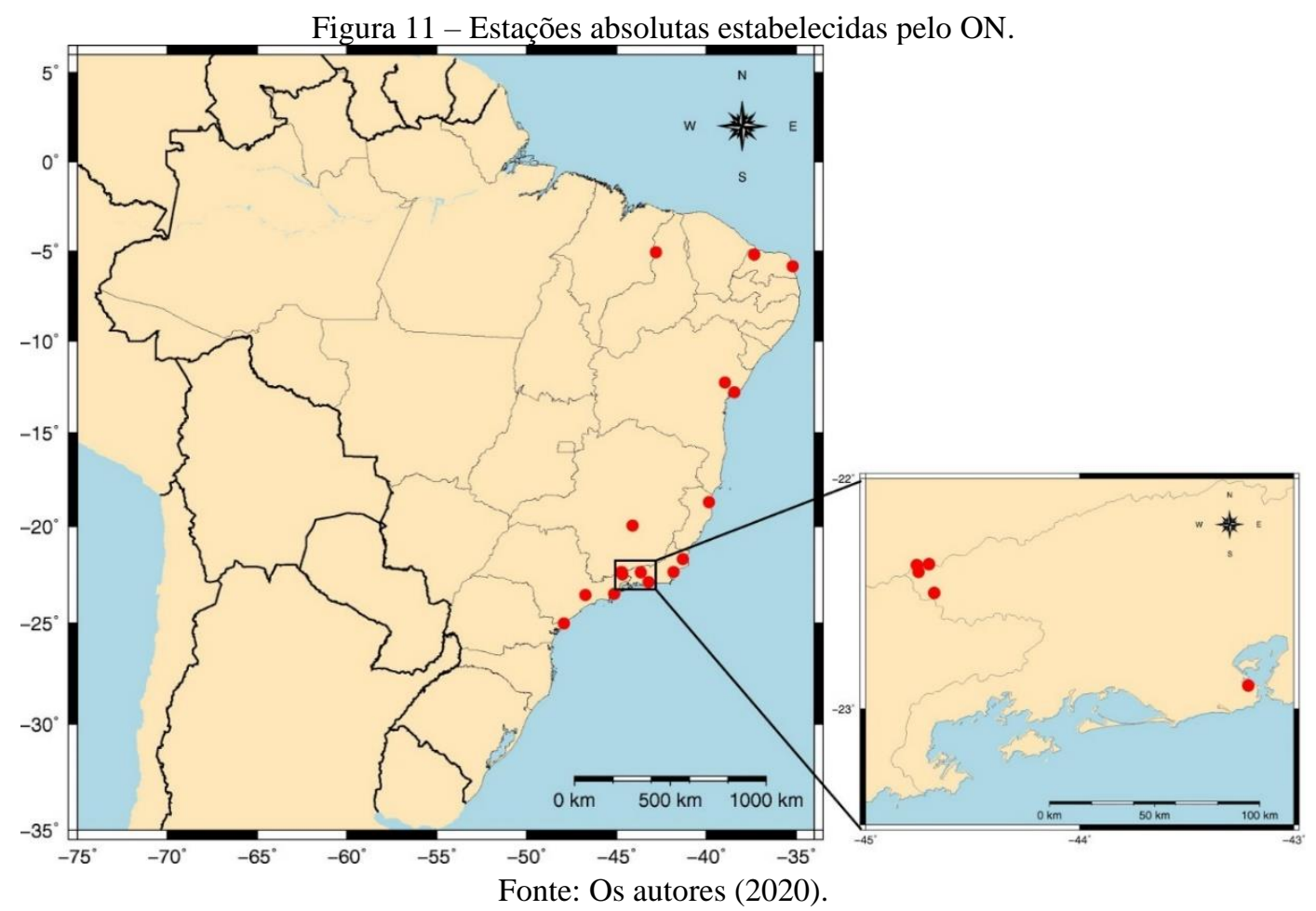

A maior parte das estações estão concentradas na costa brasileira. Um destaque deve ser dado para cinco medições conduzidas na linha de calibração "Agulhas Negras" (detalhe da Figura 11). A linha que tem início na cidade do Rio de Janeiro e se estende até o Pico das Agulhas Negras, foi determinada em 1982 por medições relativas e teve em 2006 suas estações remedidas (DE SOUSA; DOS SANTOS, 2010). 
Tabela 2 - Valor de $g$ da linha de calibração "Agulhas Negras".

\begin{tabular}{c|c}
\hline Estações & Valor de $\boldsymbol{g}$ (mGal) \\
\hline IGNS 40123A - Rio de Janeiro & $978.789,852 \pm 0,011$ \\
\hline CAL 02 - Engenheiro Passos & $978.601,078 \pm 0,006$ \\
\hline CAL 03 - Fazenda Lapa & $978.419,483 \pm 0,009$ \\
\hline CAL 04 - Marco Zero & $978.325,514 \pm 0,008$ \\
\hline CAL 05 - Posto Ibama \#03 & $978.163,000 \pm 0,008$ \\
\hline
\end{tabular}

Fonte: De Sousa e Dos Santos (2010).

No ano de 2013, o Instituto Geográfico e Cartográfico (IGC) do estado de São Paulo em cooperação com a USP e com o Centro de Estudos em Geodesia (CENEGEO) adquiriu um gravímetro absoluto n ${ }^{\circ} 032$, da marca MicroG Lacoste, modelo A-10. Com essa nova aquisição, vislumbrou-se a possibilidade do estabelecimento de novas estações absolutas, bem como remedições no país e nas Américas do Sul e Central. Dessa forma, foi estabelecida, entre 2013 a 2017, a rede absoluta no estado de São Paulo (15 estações novas e 4 reocupações). Desde 2017, com previsão de término para 2020, 26 estações estão sendo determinadas no estado de Minas Gerais (BLITZKOW et al., 2017). Além disso, outras estações foram estabelecidas nos estados do Amazonas, Rondônia, Mato Grosso e Mato Grosso do Sul.

Os deslocamentos no interior do país possibilitaram a remedição de algumas estações da RENEGA, bem como sua densificação. Conforme citado na seção 4, a rede tem servido como linha de calibração de gravímetros relativos (L\&R e SCINTREX), para determinação do fator de escala. Este tipo de operação é moroso e trabalhoso. Geralmente, 3 ou 4 equipes de campo são formadas (cada equipe possui duas pessoas), sendo responsáveis por 2 ou até 3 gravímetros. Desde o momento da chegada das equipes ao local de medição até a saída para outra estação pode-se despender de duas a três horas. No trabalho de calibração, circuitos gravimétricos são realizados, isto é, mede-se na primeira estação, desloca-se e mede-se na próxima estação e retorna para medir e assim fechar o circuito na primeira estação. Esse procedimento deve ser realizado em até 48 horas, uma vez que após esse período a deriva instrumental deixa de ser linear. Detalhes sobre o conceito de deriva instrumental podem ser encontrados em Rosier (1979) e Castro Júnior (2005). Deste modo, a conclusão da operação dentro do tempo supracitado, envolvendo os circuitos Brasília - Valinhos - Brasília e Curitiba - Santa Maria - Curitiba se torna um desafio. Face ao exposto, em 2016 foi proposto a medição de duas novas estações (Monte Carmelo - MG e Lages - SC) entre cada um dos dois trechos referidos, de forma a facilitar a logística. Ademais, foi proposto a remedição de 3 estações que compõem a RENEGA, bem como a remedição de duas estações absolutas, determinadas no passado (São Paulo e Cananeia no estado de São Paulo) (Figura 12). As medições foram conduzidas entre outubro de 2014 a janeiro de 2018.

A aquisição dos dados foi realizada a partir de um conjunto de 8 a 10 medições, com 120 observações gravimétricas de 1 segundo, totalizando desde 9.600 a 12.000 observações. O processo foi controlado por um computador que por meio do software específico do gravímetro e de modelos numéricos pré-definidos, que corrige as medidas gravimétricas realizadas dos efeitos da atração lunissolar, do movimento do polo, da carga oceânica e da pressão barométrica. $\mathrm{O}$ valor final da aceleração de gravidade absoluta foi a média de todas as observações dos diferentes conjuntos, após as correções. Posteriormente, o valor foi reduzido ao solo considerando o gradiente local obtido com um gravímetro relativo.

Durante o levantamento de campo procurou-se auferir as medições no mesmo local levantado em 1989 (implantação da RENEGA). Entretanto, em três estações não foi possível executar a medida como se desejava. $\mathrm{Na}$ estação Brasília, a observação foi conduzida na estação RECOR (medido em 1992 pelo equipamento JILAG-4). Em Viçosa, função da instabilidade do piso do local, foi escolhida uma sala distante $~ 50$ m do local anterior. Por último, em Curitiba, optou-se por medir em frente à porta principal da Igreja Senhor Bom Jesus do Cabral e não nas dependências da UFPR. Nas demais estações da RENEGA (Valinhos e Santa Maria) e nas estações São Paulo e Cananeia, o equipamento ocupou o mesmo local da primeira medida. A Tabela 3 apresenta os valores de $g$ para as novas estações e para as reocupações. 
Figura 12 - Estações RENEGA reocupadas (azul) e estações absolutas (vermelho).

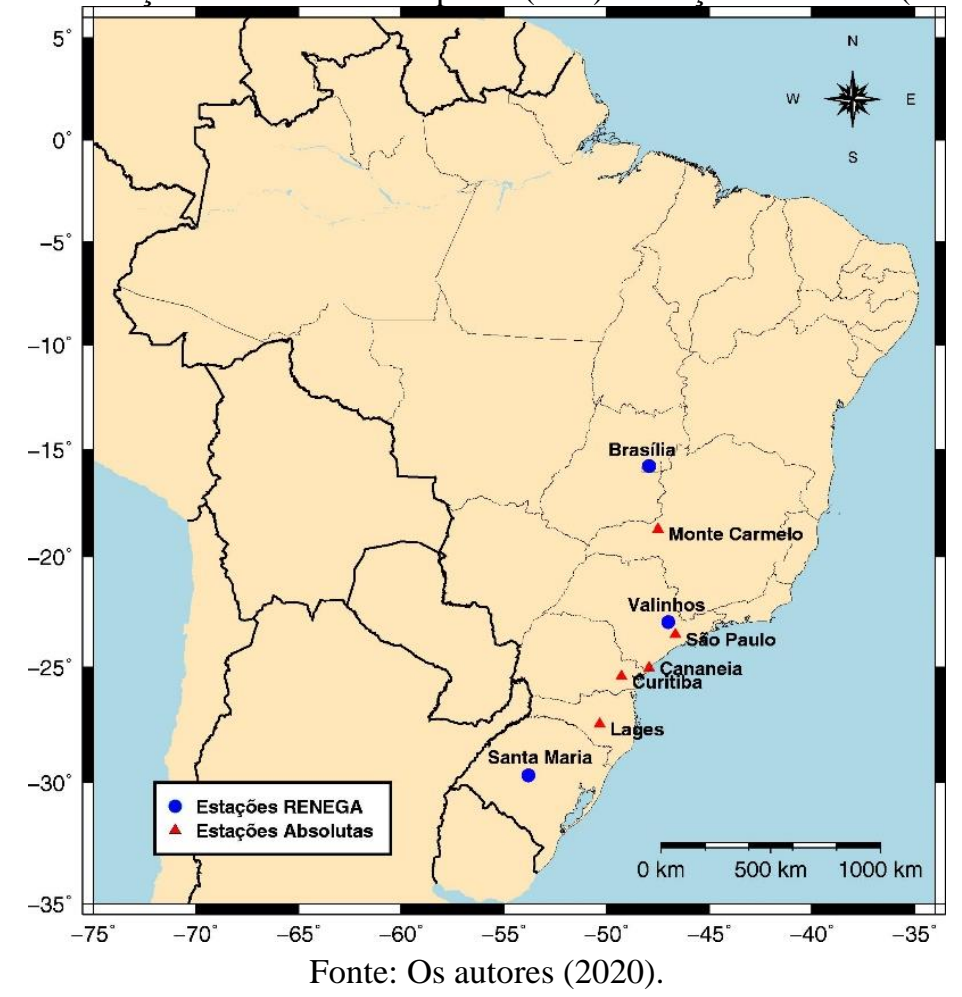

Tabela 3 - Valores de $g$ determinados entre 2014 e 2018.

\begin{tabular}{c|c}
\hline Estações & Valor de $\boldsymbol{g}$ (mGal) \\
\hline Brasília (IBGE) & $978.079,072 \pm 0,011$ \\
\hline Monte Carmelo & $978.293,411 \pm 0,011$ \\
\hline Viçosa & $978.460,307 \pm 0,011$ \\
\hline Valinhos (RENEGA) & $978.563,644 \pm 0,011$ \\
\hline São Paulo & $978.641,890 \pm 0,012$ \\
\hline Cananeia & $978.934,232 \pm 0,012$ \\
\hline Curitiba & $978.758,116 \pm 0,011$ \\
\hline Lages & $978.890,777 \pm 0,011$ \\
\hline Santa Maria (RENEGA) & $979.261,568 \pm 0,011$
\end{tabular}

Fonte: Os autores (2020).

A partir da remedição de algumas estações que compõem a RENEGA (BLITZKOW et al., 2017), bem como das estações absolutas de São Paulo e Cananeia, foi possível realizar uma comparação envolvendo 5 estações (Tabela 4).

Tabela 4 - Comparações entre as medições absolutas.

\begin{tabular}{|c|c|c|c|c|}
\hline Estações & Equipamentos & Ano & Valor de $g$ (mGal) & Diferença (mGal) \\
\hline \multirow{2}{*}{ Brasília (IBGE) } & JILAG-4 & 1992 & $978.079,100$ & \multirow{2}{*}{0,028} \\
\hline & A-10 032 & 2017 & $978.079,072$ & \\
\hline \multirow{2}{*}{ Valinhos (RENEGA) } & JILAG-3 & 1989 & $978.563,778$ & \multirow{2}{*}{0,034} \\
\hline & A-10 032 & 2017 & $978.563,744$ & \\
\hline \multirow{2}{*}{ São Paulo } & A-10 011 & 2007 & $978.641,820$ & \multirow{2}{*}{$-0,070$} \\
\hline & A-10032 & 2014 & $978.641,890$ & \\
\hline \multirow{2}{*}{ Cananeia } & A-10 011 & 2007 & $978.934,000$ & \multirow{2}{*}{0,237} \\
\hline & A-10 032 & 2014 & $978.934,237$ & \\
\hline \multirow{2}{*}{ Santa Maria (RENEGA) } & JILAG-3 & 1989 & $979.261,636$ & \multirow{2}{*}{0,068} \\
\hline & A-10 032 & 2017 & $979.261,568$ & \\
\hline
\end{tabular}

Fonte: Os autores (2020). 


\section{CONSIDERAÇÕES FINAIS}

Os avanços tecnológicos a partir dos anos 60 contribuíram de forma significativa para o desenvolvimento de gravímetros absolutos transportáveis e com precisão na ordem de microGal, possibilitando a determinação de $g$ em grande parte da superfície terrestre. A implantação da Rede Nacional de Estações Gravimétricas Absolutas no final da década de 1980, conduzida pela Universidade de Hannover e pela UFPR, contribuiu substancialmente para a evolução da infraestrutura gravimétrica no país. Adiciona-se a esse episódio, a contribuição do Observatório Nacional e, nessa última década a importante parceira envolvendo o Instituto Geográfico e Cartográfico do Estado de São Paulo com a Universidade de São Paulo e o CENEGEO o que proporcionou expandir o número de estações absolutas no país, além de remedir algumas estações pertencentes à RENEGA. Essa rede tem sido referência para a operação de calibração de equipamentos relativos (L\&R e SCINTREX).

A partir dessa década, a componente gravimétrica tem ganhado destaque no cenário geodésico, seja pela divulgação das novas altitudes a partir de números geopotenciais, disponibilizada pelo IBGE em 2018, seja pelo contínuo esforço para a implantação de um Sistema Internacional de Referência para Altitudes (International Height Reference System - IHRS). Para esse último tema, a determinação de medições absolutas é precípua nas estações que comporão o IHRS. Além disso, é importante o país possuir uma distribuição espacial homogênea de estações absolutas, uma vez que em termos de uma melhor precisão para a atividade de densificação gravimétrica (visando o cálculo de modelos geoidais ou medições de $g$ sobre Referências de Nível) deve-se considerar o início dos circuitos gravimétricos em estações absolutas. Um resumo da distribuição de estações absolutas no país é apresentado na Figura 13.

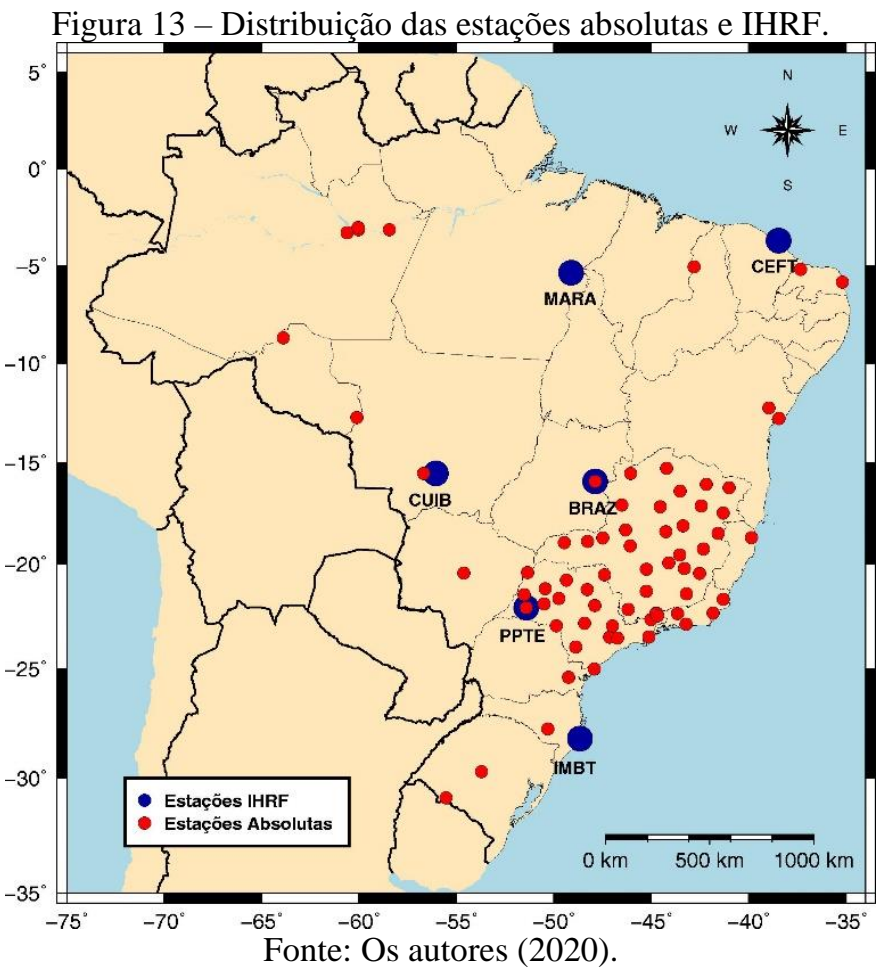

Dos 26 estados brasileiros, 14 possuem ao menos uma estação absoluta. O Distrito Federal possui uma estação na mesma localidade da futura estação IHRF. Destaque para os estados de Minas Gerais, Rio de Janeiro e São Paulo, que possuem uma distribuição homogênea, sendo que o último estado também possui uma estação absoluta na mesma localidade da estação IHRF. Esforços devem ser concentrados para a determinação de $g$ nos demais locais que comporão o IHRF, bem como no avanço para os estados ausentes de estações absolutas. Parcerias envolvendo instituições de ensino e pesquisa são fundamentais para o sucesso desse trabalho. 


\section{Agradecimentos}

Os autores agradecem ao Instituto Brasileiro de Geografia e Estatística pelo apoio dos levantamentos gravimétricos. Agradecemos também ao Instituto Geográfico e Cartográfico do estado de São Paulo pelo financiamento do equipamento. Por fim, agradecemos ao CNPq pelo apoio financeiro (Processo: 420555/2016$1)$.

\section{Contribuição dos Autores}

O primeiro autor contribuiu na conceptualização, administração do projeto, aquisição de financiamento, além da redação (minuta inicial). O segundo e terceiro autores contribuíram na curadoria dos dados, bem como na análise formal. O quarto autor auxiliou na investigação, sobretudo na coleta de informações históricas, uma vez que atua no IBGE. A última autora contribuiu na visualização (geração das figuras). Todos os coautores participaram da revisão crítica e comentários.

\section{Conflitos de Interesse}

Os autores declaram que não há conflitos de interesse.

\section{Referências}

ALDER, K. A Medida de Todas as Coisas. Editora Objetiva, 2003.

AMALVICT, M. Absolute Gravimetry at BIPM. In: MERTIKAS, S.P. (ed.) Gravity, Geoid and Earth Observation IAG Commission 2: Gravity Field. International Association of Geodesy Symposia: Verlag Berlin Heidelberg. pp 83-92. 2010.

AGÊNCIA NACIONAL DO PETRÓLEO (ANP). Gravimetria. Banco de Dados Gravimétricos. Rio de Janeiro. Disponível em: <https://www.anp.gov.br/site/extras/sftp/index.html?lang=pt-BR> Acesso em: 15 fev. de 2019.

BLITZKOW, D.; MATOS, A. C. O. C.; BATISTTI, A.; BJORKSTROM, I. M. Red Gravimétrica Absoluta em América del Sur. In: Simposio SIRGAS 2017 Mendoza, Argentina, Apresentações. 2017. Disponível em: <http://www.sirgas.org/en/sirgas-symposia/mendoza_2017/>.

CARTER, W. E.; PETER, G.; SASAGAWA, G. S.; KLOPPING, F. J.; BERSTIS, K. A.; FALLER, J. E.; NORCROSS, D. W.; HILT, R. L.; NELSON, P.; CHRISTY, G. L.; NIEBAUER, T. M.; HOLLANDER W.; SEEGER, H.; RICHTER, B.; WILMES, H.; LOTHAMMER, A. The new FG5 absolute Gravimeter National Oceanic and Atmospheric Administration. Estados Unidos. Technical Report. 1994.

CASTRO JÚNIOR, C. A. C. Contribuição ao estabelecimento de um sistema gravimétrico para a América do Sul. 2005. 156p. Dissertação (Mestrado em Engenharia de Transportes), Escola Politécnica, Universidade de São Paulo, São Paulo, 2005.

CASTRO JÚNIOR, C. A. C.; GUIMARÃES, G. N.; FERREIRA, N. C. Evolução da Infraestrutura Gravimétrica no Brasil. Revista Geociências, Rio Claro. v. 37, n. 2, pp. 361-384. 2018.

COOK, A.H. The Absolute Determination of the Acceleration Due to Gravity. Metrologia, v.1, n. 3, 1965. pp. 84-114.

DE FREITAS, S.R.C. Atividades gravimétricas da UFPR [mensagem pessoal]. Mensagem enviada por Silvio Rogério Correia de Freitas, Professor Doutor do Curso de Pós-Graduação em Ciências geodésicas, UFPR, <sfreitas350@gmail.com>.Em 10 jun. 2015.

FALLER, J. E.; GUO, Y. G.; GSCHWIRD, J.; NIEBAUER, T. M.; RINKER, R. L.; XUE, J. The JILA Portable Absolute Gravity Apparatus. Defense Mapping Agency Hydrographic/Topographic Center. Estados Unidos. Technical Report. 983. 
GREEN, C. M.; FAIRHEAD J. D. The South America Gravity Projet. Wolfgang Torge Alvaro González Fletcher James G. Tanne Recent Geodetic and Gravimetric Research in Latin America Springer-Verlag Berlin Heidelberg. p. 82-95. 1993.

GEMAEL, C. Introdução a Geodésia Física. Curitiba: Editora UFPR, 1999.

GEMAEL, C.; LEITE, O.H.S.; ROSIER, F.A.; TORGE, W.; ROOER, R.H.; SCHNULL, M. Large-Scale Absolute Gravity Control in Brazil. In: RUMMEL, R. (ed.); HIPKIN, R. G. (ed.). Gravity, Gradiometry and Gravimetry. International Association of Geodesy Symposia 103: Springer-Verlag. pp 49-56. 1990

GEMAEL, C.; DE FREITAS, S. R. C.; FAGGION, P. L.; SILVA JUNIOR, J. S.; SIMÕES, K. Rede Gravimétrica Científica para o Estado do Paraná. In: Simpósio Brasileiro de Geomática, 2002, Presidente Prudente, Anais... pp. 105-109. 2002.

GOMES, R. A. A. D.; MOTTA, A. C. Projeto Levantamento Gravimétrico no Estado da Bahia. Relatório Final. Textos e Mapas. Salvador, CPRM. Convênio DNPM/CPRM, 140 p. 1980.

INSTITUTO BRASILEIRO DE GEOGRAFIA E ESTATÍSTICA (IBGE). Sistema Geodésico Brasileiro. Rio de Janeiro. Disponível em: <https://ww2.ibge.gov.br/home/geociencias/geodesia/gravimetrica.shtm>. Acesso em: 15 fev. de 2019.

INOUE, M.E.B.; GUIMARÃES, G.N.; MATOS, A.C.O.C.; BLITZKOW, D. Calibração dos gravímetros L\&R e CG-5 na Rede Nacional de Estações Gravimétricas Absolutas - RENEGA. In: VII Simpósio Brasileiro de Ciências Geodésicas e Tecnologias da Geoinformação, 2018, Recife, Anais... pp. 543 -549, 2018.

MELCHIOR, P. Gravimetric measuring techniques. In: Physical Methods, Instruments and Measurements, Encyclopedia of Life Support System EOLSS 2, pp. 259-290. 2008.

MELLO, M.P. Sistema Geodésico Brasileiro: ensaio para definição do vetor de orientação geocêntrica através da geodésia física. Curitiba, 1973. 268p. Dissertação (Mestrado em Ciências Geodésicas), Universidade Federal do Paraná. Curitiba. 1973.

MICRO-G LACOSTE. A-10 Portable Gravimeter User's Manual. 2008. 59p. Disponível em: $<$ http://microglacoste.com/support/product-manuals/attachment/a-10manual/>

MOREIRA, I.C. A expedição de Couplet à Paraíba: 1698. Revista da Sociedade Brasileira de História da Ciência, São Paulo v. 5, p. 23-31, 1991.

NIEBAUER, T. M.; SASAGAWA. G. S.; FALLER, J. E.; HILT, R. KLOPPING, F. A new generation of absolute gravimeters. Metrologia, v. 32, p. 159-180, 1995.

OBSERVATÓRIO NACIONAL (ON). Rede Gravimétrica Fundamental Brasileira, 1976-1986. Departamento de Geofísica. Rio de Janeiro: ON, 1986. Disponível em: < http://www.on.br/>. Acesso em 20 maio 2015.

OBSERVATÓRIO NACIONAL (ON). Base de Dados Gravimétricos do Observatório Nacional. Departamento de Geofísica. Rio de Janeiro. Disponível em: < http://extranet.on.br/bdgon/gravimetria/pesquisar.php?pg=estacao\&uf=inicio>Acesso em 15 fev. de 2019.

ROSIER, F.A. Medidas diferenciais da gravidade: ajustamento de uma sub-rede de estações gravimétricas e determinação de coeficientes de escala para os gravímetros LaCoste \& Rombert modelo G no 41, 371 e 454. 1979. 190 p. Dissertação (Mestrado), Curso de Pós-graduação em Ciências Geodésicas, Universidade Federal do Paraná, Curitiba. 1979.

SNEEUW, N. Physical Geodesy. Lecture Notes. Institute of Geodesy Universität Stuttgart 2006 137p.

DE SOUSA, M.A.; DOS SANTOS, A.A. Absolute Gravimetry on the Agulhas Negras Calibration Line Revista Brasileira de Geofísica, Rio de Janeiro, v. 28, n. 2, pp 165-174, 2010.

SUBIZA PIÑA, W.H.; DE SOUSA, M.A. O estado da base de dados gravimétricos Nacional (BDG-ON). Situação em junho, 2001. Revista Brasileira de Geofísica, Rio de Janeiro, vol. 19, n. 3, pp 325-328, 2001.

TIMMEN, L.; GITLEIN, 0.; MÜLLER, J.; STRYKOWSKI, G.; FORSBERG, R. Absolute Gravimetry with the Hannover Meters JILAg-3 and FG5-220, and their Deployment in a Danish-German 
Cooperation. Zeitschrift fur Geodasie Geoinformation und Landmanagement, v. 3, n. 133, 2008. pp 149-163.

TORGE, W.; RÖDER, R. H.; SCHNÜLL, M.; WENZEL, H. -G. First results with the transportable absolute gravity meter JILAG-3. Bulletin Géodésique, v. 61, pp 161-176. 1987.

TORGE, W. Geodesy. compl. rev. and ext. ed. Berlin: Walter de Gruyter, 1991.

TORGE, W.; TIMMEN, L.; RÖDER, R. H.; SCHNÜLL, M. The IFE Absolute Gravity Program "South America" 1988 - 1991. Report. Deutsche Geodätische Kommission, München, 1994. 45 p.

TORGE, W.; MÜLLER, J. Geodesy. Editora de Gruyter; 4th ed. 2012.

VEIGA, L. A.; NADAL, C. A.; FAGGION, P. L.; WANDRESEN, R.; DE FREITAS, S. R.; STROPARO, E. M. Camil Gemael: uma vida dedicada à Geodésia. Revista Brasileira de Cartografia, Uberlândia, v. 70, n. 3, p. $745-786,30$ set. 2018.

\section{Biografia do autor principal}

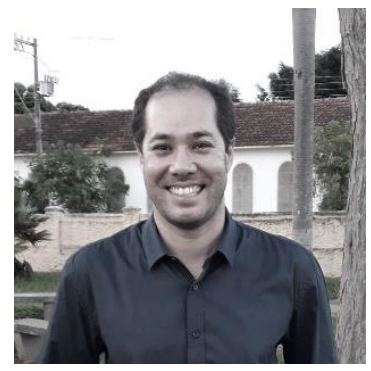

Gabriel do Nascimento Guimarães, Franca, 1984. Engenheiro Cartógrafo formado em 2007, pela Faculdade de Ciências e Tecnologia da Universidade Estadual Paulista, Campus Presidente Prudente. Mestre em Engenharia de Transportes pela Escola Politécnica da Universidade de São Paulo (em 2010). Doutor também pela EPUSP e pelo Politecnico di Milano, Itália, em 2013. Atualmente, é docente no curso de Engenharia de Agrimensura e Cartográfica pela Universidade Federal de Uberlândia, Campus Monte Carmelo. Atua nas áreas de sistema vertical, modelagem geoidal e modelos do geopotencial. 